\title{
Degradable, absorbable or resorbable-what is the best grammatical modifier for an implant that is eventually absorbed by the body?
}

\author{
Yang Liu ${ }^{1}$, Yufeng Zheng ${ }^{1 *}$ and Byron Hayes ${ }^{2}$
}

\begin{abstract}
The adoption of grammatical modifier for implants or other kinds of biomaterials eventually absorbed by the body has been a long-standing confusing issue, and there are diverse terms in the large fields of research, which not only causes the difficulties when searching on the Internet, but also blurs the meaning and boundaries for researchers. Prior unification attempts at laws/standards set the basis for such research fields towards researching, labeling, marketing and instructions for use. Considering this, the typical grammatical modifiers "biodegradable", "resorbable", "absorbable", along with their noun forms used in the decades of scientific research have been reviewed and explained, interdisciplinary in chemistry, ecology, materials science, biology, microbiology, medicine, and based on usage customs, laws, standards and markets. The term "biodegradable" has been not only used in biomaterials but also in ecology waste management, biomedicine and even natural environment. Meanwhile, the term "resorbable" has long been used in biological reaction (osteoclast driven bone resorption), but is inappropriate for implants that do not carry the potential to grow back into their original form. The term "absorbable" focuses more on the host metabolism to the foreign biodegradation products of the implanted material/device compared with the term "degradable/biodegradable". Meanwhile the coherence and normalization of the term "absorbable" carried by its own in laws and standards contributes as well. In general, the authors consider the term "absorbable" to be the best grammatical modifier with respect to other adjectives which share the same inherence. A further internationally unified usage is proposed by us.
\end{abstract}

Keywords: biodegradation, bioabsorption, bioresorption, biodegradable, absorbable, biomaterials

\section{INTRODUCTION}

\section{Current situation}

Technologies labeled as absorbable, bioabsorbable, resorbable, bioresorbable, degradable, biodegradable, or by some other similar terms, all of which carry the inherent underlying potential to allow treated tissue to return to its native state, have been developed for a long time. More specifically, it likely started with the use of sheep gut guitar strings (made of natural collagens, recognized as absorbable polymer today) to approximate wounds over 2,000 years ago in the Roman Empire [1]. As time and technology progressed, the catgut suture technology became significantly refined and synthetic polymers were also developed, both of which led to the absorbable sutures we find in broad use today. Resorbable bioceramic technologies also entered into use as bone fillers [2,3]. In addition, the newly evolving biodegradable metals (such as $\mathrm{Mg}, \mathrm{Fe}$, and $\mathrm{Zn}$ and their alloys) are now making their way into the commercial marketplace [4,5]. All these devices carry the promise of fulfilling their intended initial physical/mechanical function and then undergoing compositional conversion into components that are eventually absorbed by the body.

Meanwhile, numerous terms have been used to describe the same general concept, with the diversity of terms providing self-evidence of either the absence or non-adherence to standard terminology. Compounding this nomenclature dilemma, literature in the field of absorbable/biodegradable/resorbable implant materials has been increasing exponentially since the mid-1980s when the synthetic alpha-

\footnotetext{
${ }^{1}$ Department of Materials Science and Engineering, College of Engineering, Peking University, Beijing 100871, China

${ }^{2}$ Biomaterials Research and Development, Medical Product Division, W.L. Gore \& Associates, Inc, Flagstaff, Arizona 86003, USA

*Corresponding author (email: yfzheng@pku.edu.cn)
} 
hydroxyester polymeric resins first became broadly available from commercial suppliers. To attain a preliminary understanding of the scope of the confusion surrounding labeling of these implants, all any person has to do is to initiate an Internet search, which-in order to confidently address a single simple concept-begins as a convoluted asterisk-filled multi-line query.

Such problem not only causes the difficulties when searching on the Internet, but also blurs the meaning and boundaries for researchers. The absence of any universal term recognition unnecessarily complicates communication and confounds the selection of language for research papers, legal descriptions, international trade agreements, as well as the language used in an implant's labeling, marketing, and instructions for use. Regardless of its obviousness, the problem has been a present and fully recognized problem that has persisted for decades. Some intermittent attempts have been made by researchers to unify this disparate language into a single preferred term [6,7]. As a result, multiple purportedly "definitive" papers have been published through the years. However, many of these papers reflect the perspective of a single author or society, which often leads to conflicts between nomenclature preferences [8-13] for even a single professional society's breadth of view can be similarly limited by its own scope. Materials that are absorbed by the body do span many medical disciplines, and the breadth of the technology's applicability may contribute toward inhibiting any one professional society from attempting a nomenclature resolution-as can be evidenced at numerous conferences where one can observe an internal array of presentations and posters with titles and terminology spanning most (if not all) the terms described in the $1^{\text {st }}$ sentence.

\section{Standards development in advance}

Typically absent from most of these historical nomenclature recommendations was any comprehensive consideration of the truly broader medical context contained within medical dictionaries and the relevant pharmacopeial and/or implantable device-related standards [14]. Early device and pharmaceutical companies, regulators, and any of the involved standards development organizations all had to consciously think about and decide on the specific terms to include on their labels and in any governing standard, regulation, and/or law. With implants that are eventually absorbed by the body, the selection and standardization of terminology by the United States Pharmacopeia had already occurred and had fully focused on the term ABSORBABLE by 1939 through its official des- ignations of both ABSORBABLE and NONABSORBABLE sutures $[15,16]$. This same standardized language and classifications remain in place today and have been for decades embedded in both United States Federal laws and US-Food and Drug Administration (FDA) regulations [17-19] (to be discussed in later section), as well as in the United States, British, and European Pharmacopeias [20-22]. Trying to change or reverse what has already been both functional and established in both regulations and law (now for decades) is both difficult and a questionable undertaking. Regardless of this historic and significant establishment of ABSORBABLE as standardized terminology, it is possible that a simple lack of awareness and/or rigorous review by those involved in the broader research and clinical fields may have become the source for the plethora of similar and analogously utilized terms we routinely encounter today.

The advances in standard unification of the grammatical modifier provide insights to the term usage in the research of such field. Due to the fact that many grammatical modifiers have been used in this field for a long time, typical terms have been reviewed and explained, interdisciplinary in chemistry, ecology, materials science, biology, microbiology, medicine, and based on usage habits, laws, standards and markets. Furthermore, the international unification of the grammatical term usage is proposed.

\section{TERMINOLOGY}

As stated in the opening sentence, multiple terms are being utilized to describe the same general absorbable implant concept, which includes absorbable, bioabsorbable, resorbable, bioresorbable, degradable, biodegradable, and potentially other similar themes. To provide an improved understanding of the scope of current language diversity, an overview of the usage of the aforementioned words was undertaken to provide data that assisted in both confirming and clarifying the scope of the problem. The results are intended to provide a summary understanding of the scope of confusion (i.e., how big the problem really is) so as to better facilitate identification of an appropriate remedy.

\section{Overview of utilization of the terms "degrada-}

\section{tion"/“biodegradation" and "degradable"/“biodegradable"}

"Degradation" and "biodegradation" are both used in polymers and ceramics for a period of time, and had been noted by Prof. D. Williams as "the process as deleterious change in the chemical structure, physical properties, or appearance of a material" according to the American Society for Testing and Materials (ASTM) [23]. In the research of "biorelated" polymers, International Union 
of Pure and Applied Chemistry (IUPAC) suggested that "degradation indicates progressive loss of the performance or of the characteristics of a substance or a device" [14]. It is also a general process since there can be degradations caused by the action of water named "hydrodegradation" or hydrolysis. As for biorelated polymers, the degradation process is limited to macromolecule cleavage and molar mass decrease, which distinguishes the degradation of biorelated polymer from fragmentation and disintegration illustrated in bioceramics. The term "degradation" was formerly used in bioceramics by Prof. L. Hench to describe the decomposition process of calcium phosphate ceramics, which was followed by host response and tissue repair [3]. Thus the definition of "degradation" used in polymers and ceramics fields could be interpreted as different, inferring more specifically to chemical processes for bio-related polymers while referring to physical break down from the view of bio-ceramics researchers.

As for the term "biodegradation", it is not the simple addition of the prefix "bio-" to "degradation". Fig. 1 describes the common usage of "biodegradation" currently. The word was firstly introduced as the consumption of material by bacteria, fungi, or other biological means in ecology, waste management, biomedicine and even natural environment [24]. Some kinds of environmentally friendly products also undergo such process as they can be degraded by microorganisms and do no harm to the environment. However, some researchers studying polymers and ceramics have defined a more specific scope for "biodegradation". For polymers, especially biorelated polymers, the difference between "biodegradation" and "degradation" lies in the involvement of enzymatic process $[14,25]-$ a distinction that can be problematic if both modes are active in an implant's degradation process. Moreover, IUPAC stressed the importance of proved degradation mechanisms when using "biodegradation", otherwise "degradation" should be used instead of "biodegradation". In general, "degradation" and "biodegradation" both refer to the chain scission or chain cleavage. Nevertheless, the meaning of "biodegradation" in bioceramics is different since there is no such process as chain scission. The degradation process of so-called "resorbable ceramics" is claimed to involve either decomposition to small particles as well as dissolved ions, which participate in the enzyme/cell mediated reaction and new tissue forms $[3,26-28]$. Despite the exact degradation process still needs further investigations, the word "degradation" used for "resorbable" ceramics expresses multiple meanings covering both chemical and physical reactions in physiological environment such as hydrolysis, decomposition and debris formation. According to Prof. D. Williams, the recommended definition of "biodegradation" is the gradual breakdown of a material mediated by

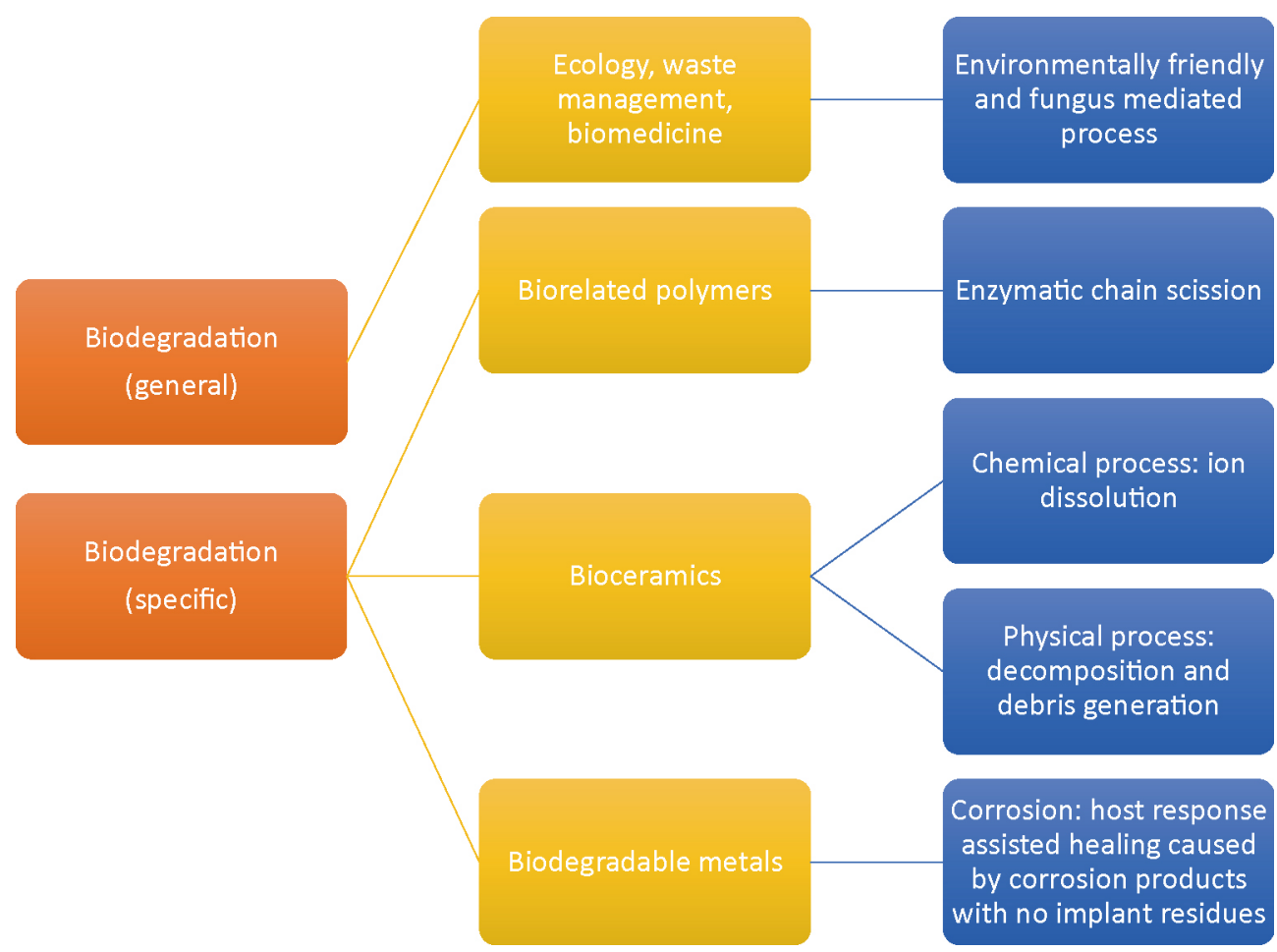

Figure 1 Common use of biodegradation currently. 
specific biological activity [23]. Another definition, as the biomaterial or medical device involving loss of their integrity or performance when exposed to a physiological or simulated environment, which existed in some ISO Technical Report, was not recommended since no specific respect to biological activity mentioned [23].

Beyond the category of biomaterials, "degradable" in pure chemistry was defined as qualifier to a substance that can undergo physical and/or chemical deleterious changes of some properties especially of integrity under stress conditions [14]. Thus degradable polymer is considered with macromolecules being able to undergo chain scissions, resulting in a decrease of molar mass [14]. Besides, ASTM made a standard definition on "degradable" in the scope of soil, rock, and contained fluids as "in erosion control, decomposes under biological, chemical processes, or ultraviolet stresses associated with typical application environments" [29]. Despite no specific emphasis on biomaterials, numerous publications used "degradable" to modify metals, polymers or compounds in tissue engineering, drug delivery and gene delivery [30-35]. Meanwhile, in some ASTM standard specifications, the definition of the adjective "biodegradable" is given as capable of decomposing under natural conditions into elements found in the nature [36-42]. The active ASTM entries currently with "biodegradation", "degradable" and "biodegradable" in the title are summarized in Table 1 . The adoptions of "biodegradation", "degradable" and "biodegradable" by ASTM are historical generally in the classification of ecology or environmental protection.

While the above listing provides evidence that the usage of the term biodegradable is broad, it is particularly notable that almost all of the listed standards are not relevant to implantable devices. Instead, the listing primarily reflects usage directed toward the environmental degradation aspect that is most commonly recognized within the broader non-medical oriented population. ASTM-F1635, a standard specifically centered on the hydrolytic degradation

Table 1 Summary of the terms "biodegradation", "degradable" and "biodegradable" being utilized in ASTM titles (not limited to implant)

\begin{tabular}{|c|c|}
\hline Terminology & ASTM titles \\
\hline \multirow{10}{*}{ Biodegradation } & $\begin{array}{l}\text { ASTM D5864-11 Standard Test Method for Determining Aerobic Aquatic Biodegradation of Lubricants or Their } \\
\text { Components }\end{array}$ \\
\hline & $\begin{array}{l}\text { ASTM D6954-04(2013) Standard Guide for Exposing and Testing Plastics that Degrade in the Environment by a } \\
\text { Combination of Oxidation and Biodegradation }\end{array}$ \\
\hline & $\begin{array}{l}\text { ASTM D5511-12 Standard Test Method for Determining Anaerobic Biodegradation of Plastic Materials Under High-Solids } \\
\text { Anaerobic-Digestion Conditions }\end{array}$ \\
\hline & $\begin{array}{l}\text { ASTM D6139-11 Standard Test Method for Determining the Aerobic Aquatic Biodegradation of Lubricants or Their } \\
\text { Components Using the Gledhill Shake Flask }\end{array}$ \\
\hline & $\begin{array}{l}\text { ASTM D7991-15 Standard Test Method for Determining Aerobic Biodegradation of Plastics Buried in Sandy Marine } \\
\text { Sediment under Controlled Laboratory Conditions }\end{array}$ \\
\hline & $\begin{array}{l}\text { ASTM D5338-15 Standard Test Method for Determining Aerobic Biodegradation of Plastic Materials Under Controlled } \\
\text { Composting Conditions, Incorporating Thermophilic Temperatures }\end{array}$ \\
\hline & $\begin{array}{l}\text { ASTM D6691-09 Standard Test Method for Determining Aerobic Biodegradation of Plastic Materials in the Marine } \\
\text { Environment by a Defined Microbial Consortium or Natural Sea Water Inoculum }\end{array}$ \\
\hline & $\begin{array}{l}\text { ASTM D5526-12 Standard Test Method for Determining Anaerobic Biodegradation of Plastic Materials Under Accelerated } \\
\text { Landfill Conditions }\end{array}$ \\
\hline & $\begin{array}{l}\text { ASTM D7475-11 Standard Test Method for Determining the Aerobic Degradation and Anaerobic Biodegradation of Plastic } \\
\text { Materials under Accelerated Bioreactor Landfill Conditions }\end{array}$ \\
\hline & ASTM D5988-12 Standard Test Method for Determining Aerobic Biodegradation of Plastic Materials in Soil \\
\hline \multirow{3}{*}{ Degradable } & $\begin{array}{l}\text { ASTM F1635-11 Standard Test Method for in vitro Degradation Testing of Hydrolytically Degradable Polymer Resins } \\
\text { and Fabricated Forms for Surgical Implants }\end{array}$ \\
\hline & ASTM D7444-11 Standard Practice for Heat and Humidity Aging of Oxidatively Degradable Plastics \\
\hline & $\begin{array}{l}\text { ASTM D3826-98(2013) Standard Practice for Determining Degradation End Point in Degradable Polyethylene and } \\
\text { Polypropylene Using a Tensile Test }\end{array}$ \\
\hline \multirow{3}{*}{ Biodegradable } & ASTM D7665-10(2014) Standard Guide for Evaluation of Biodegradable Heat Transfer Fluids \\
\hline & ASTM D8029-16 Standard Specification for Biodegradable, Low Aquatic Toxicity Hydraulic Fluids \\
\hline & ASTM D7044-15 Standard Specification for Biodegradable Fire Resistant Hydraulic Fluids \\
\hline
\end{tabular}


testing of absorbable polyesters, is the sole listed standard from ASTM Committee F04-Medical and Surgical Implants and, thereby, is directly relevant to implantable devices. However, this standard utilizes the term degrade and its derivatives specifically in reference to the process of degradation that occurs as a result of ester hydrolysis. Conversely, the same standard uses the term absorbable to describe a class of implants that are eventually absorbed by the body, which it defines as: "absorbable, adj-in the body-an initially distinct foreign material or substance that either directly or through intended degradation can pass through or be assimilated by cells and/or tissue."

\section{Overview of utilization of the terms "absorption"/“bioab- sorption" and "absorbable"/"bioabsorbable"}

The term "absorption" was recognized by IUPAC as the process of penetration and diffusion of a substance (absorbate) into another substance (absorbent) as a result of the action of attractive phenomena. The IUPAC definition is within the scope of chemistry. As for biomaterials, Prof. D. Williams adopted the definition in Dorland Medical Dictionary as the uptake of substances into or across tissues [23]. For this kind of definition, "absorption" emphasizes the interaction of materials and human or animal tissue. The same connotation is shared by its derivative words "absorbable" and "bioabsorbable", as capable of being degraded or dissolved and subsequently metabolized within an organism [23]. Besides, the prefix "bio-" is abridged as it is redundant in the field of implantation [43]. ASTM has made standard definition on "absorbable" in the field of absorbable polymers as well as absorbable metals, which it defines as "... an initially distinct foreign material or substance that either directly or through intended degradation can pass through or be metabolized or assimilated by cells and/or tissue in the body" [43]. Table 2 summarizes the currently active ASTM standards and both United States and European Pharmacopeia implantable device monographs that utilize the word "absorbable" in the title. Distinctly different from "biodegradable", the utilization of "absorbable" displays a distinct preference for use in describing this particular class of biomedical materials and devices.

As can be observed in both Table 1 and Table 3, the well-established terminology for describing sutures is very broadly based on the term absorbable, with historical application of the term to the original gut sutures and even extending to permanent sutures through the "nonabsorbable" descriptor.

Aside from the language of standards organization, the terminology utilized by regulatory agencies is also of particular relevance. Through multiple laws and regulations the US-FDA is authorized to evaluate medical device manufacturers and their products. The US Code of Federal Regulations (CFRs) that is specific to sutures legally describes those regulated devices based on composition and then designates both their product class and needs to meet USP requirements. While Table 3 demonstrates both a US-

Table 2 "Absorbable" utilized in title entries for implantable device related standards

\begin{tabular}{|c|c|}
\hline Terminology & Title entries \\
\hline \multirow{15}{*}{ Absorbable } & ISO/TS 17137:2014 Cardiovascular implants and extracorporeal systems-Cardiovascular absorbable implants \\
\hline & ISO/TR 37137:2014 Biological evaluation of medical devices-Guidance for absorbable implants \\
\hline & ASTM F3036-13 Standard Guide for Testing Absorbable Stents \\
\hline & ASTM F2902-16 Standard Guide for Assessment of Absorbable Polymeric Implants \\
\hline & ASTM F2502-16 Standard Specification and Test Methods for Absorbable Plates and Screws for Internal Fixation Implants \\
\hline & ASTM F1983-14 Standard Practice for Assessment of Selected Tissue Effects of Absorbable Biomaterials for Implant Applications \\
\hline & ASTM F3160-16 Standard Guide for Metallurgical Characterization of Absorbable Metallic Materials for Medical Implants \\
\hline & $\begin{array}{l}\text { United States Pharmacopoeia (USP 39/NF 34) monograph } \\
\text { "Absorbable Surgical Suture" }\end{array}$ \\
\hline & $\begin{array}{l}\text { United States Pharmacopoeia (USP 39/NF 34) monograph } \\
\text { "Nonabsorbable Surgical Suture" }\end{array}$ \\
\hline & European Pharmacopoeia (8.8) \\
\hline & “Sterile non-absorbable sutures”- 1118 \\
\hline & European Pharmacopoeia (8.8) \\
\hline & "Sterile synthetic absorbable braided sutures" - 1122 \\
\hline & European Pharmacopoeia (8.8) \\
\hline & Sterile synthetic absorbable monofilament sutures - 1123 \\
\hline
\end{tabular}


Table 3 US-FDA suture product codes and accompanying citation of US CFRs ${ }^{\text {a) }}$

\begin{tabular}{|c|c|c|}
\hline Suture name & Regulation & Product code \\
\hline Absorbable polydioxanone surgical (PDS) suture & 21 CFR878.4840 & NEW \\
\hline Absorbable poly(glycolide/L-lactide) surgical suture & 21 CFR878.4493 & GAM \\
\hline Absorbable gut suture & 21 CFR878.4830 & GAL \\
\hline Nonabsorbable poly(ethylene terephthalate) suture & 21 CFR878.5000 & GAT \\
\hline Nonabsorbable polypropylene surgical suture & 21 CFR878.5010 & GAW \\
\hline Nonabsorbable polyamide surgical suture & 21 CFR878.5020 & GAR \\
\hline Natural nonabsorbable silk surgical suture & 21 CFR878.5030 & GAP \\
\hline Stainless steel surgical suture & 21 CFR878.4495 & GAQ \\
\hline $\begin{array}{l}\text { Nonabsorbable expanded polytetrafluoroethylene (ePTFE) } \\
\text { surgical suture }\end{array}$ & 21 CFR878.5030 & NBY \\
\hline
\end{tabular}

a) Note: this table selects abbreviated results obtained from online search for the implant device term "suture" that was conducted on 6 Aug 2016 at: http://www.accessdata.fda.gov/scripts/cdrh/cfdocs/cfPCD/classification.cfm.

FDA and a US Code of Federal Regulations preference for absorbable terminology when referring to sutures, Table 4 shows an expansion of that preference to include a total of 30 absorbable implant product classifications, each of which is assigned to a relevant Federal regulation that utilizes the term "absorbable".

In short, "absorbable" is both a historically well established and currently relevant term in both the regulation and standardization of implants that are intentionally absorbed by the body.

\section{Overview of utilization of the terms "resorption"/"biore-} sorption" and "resorbable"/"bioresorbable"

In the scope of chemistry, the term "resorption" was used to illustrate the total elimination of a substance from its initial place caused by physical and/or chemical phenomena [14]. Besides the understanding from pure chemistry, "resorption" is more recognized involved in the metabolic activities in vivo. For example, "resorption" is considered as the "absorption" into the circulatory system of cells or tissue, which usually includes bone resorption, tooth resorption and vanishing twin [44]. In the biomedical scope, Prof. D. Williams used the meaning in Dorland Medical Dictionary as "lysis and assimilation of a substance, as of bone" [23]. "Bioresorption" is more common when describing the in vivo process of a certain foreign material. The ISO defined "bioresorption" as a process by which biomaterials are degraded in the physiological environment and the by-product are eliminated or completely bioabsorbed [23]. Thus, according to this interpretation, the bioresorption process includes material removal in vivo either by cellular activity or not. Conversely, Taber's Cyclopedic Medical Dictionary [45] describes the term "resorb" as the meaning "to ab- sorb again"-something that live tissue does but not something any implant is known to do-be it permanent or absorbable.

As for the adjectives "bioresorbable" and "resorbable", there is no difference when used to describe a kind of materials which have the ability of resorption. This is ascribed to the fact that "resorption" itself already has been well recognized as a biological process [23]. Currently there is no ASTM entries used "resorbable" or "bioresorbable" in the title.

\section{Utilization and comparison of the terms "biodegradable metals" and "absorbable metallic materials"}

"Biodegradable metals" generally include the metals $\mathrm{Mg}, \mathrm{Fe}$ and $\mathrm{Zn}$ and their alloys and composites. They can be defined as metals that assist with tissue healing and are then expected to gradually corrode and release corrosion products in vivo with an appropriate host response and then dissolve completely with no implant residues [46]. As a result and different from traditional "bio-inert" metallic biomaterials (e.g., Ti and Co based alloys) that release limited corrosion products [47], metabolic reactions besides inflammation can be expected to occur between the biodegradable metal and the host body after implantation. Additionally, the corrosion-based degradation mechanism of these materials is inherently different from that of either bioceramics or polymers, which has resulted in limited to no standardized guidance available from either ASTM or ISO.

Instead of the term "biodegradable metal", the recently published and first absorbable metal related standard ASTM F3160 utilizes the more inclusive word "absorbable" within the phrase "absorbable metallic materials" and, again, defines the term as “... an initially distinct foreign 
Table 4 US-FDA absorbable implant related product codes, descriptions, and accompanying CFRs ${ }^{\text {a) }}$

\begin{tabular}{|c|c|c|c|c|}
\hline Product code & Device & Device class & Regulation number & Regulation description \\
\hline OMT & Absorbable lung biopsy plug & 2 & [878.4755] & Absorbable lung biopsy plug \\
\hline LMF & Agent, absorbable hemostatic, collagen based & 3 & [878.4490] & Absorbable hemostatic agent and dressing \\
\hline LMG & Agent, absorbable hemostatic, non-collagen based & 3 & [878.4490] & Absorbable hemostatic agent and dressing \\
\hline MRY & Appliances and accessories, fixation, bone, absorbable single/multiple component & 2 & [888.3040] & Smooth or threaded metallic bone fixation fastener \\
\hline PBQ & Fixation, non-absorbable or absorbable for pelvic use & 2 & {$[884.4530]$} & Obstetric-gynecologic specialized manual instrument \\
\hline HQJ & Implant, absorbable, (scleral buckling methods) & 2 & {$[886.3300]$} & Absorbable implant (scleral buckling method) \\
\hline OWT & Mesh, surgical, absorbable, abdominal hernia & 2 & [878.3300] & Surgical mesh \\
\hline OXM & Mesh, surgical, absorbable, fistula & 2 & {$[878.3300]$} & Surgical mesh \\
\hline OXI & Mesh, surgical, absorbable, large abdominal wall defects & 2 & {$[878.3300]$} & Surgical mesh \\
\hline OXL & Mesh, surgical, absorbable, organ support & 2 & [878.3300] & Surgical mesh \\
\hline OWW & Mesh, surgical, absorbable, orthopaedics, reinforcement of tendon & 2 & [878.3300] & Surgical mesh \\
\hline OXF & Mesh, surgical, absorbable, plastic and reconstructive surgery & 2 & {$[878.3300]$} & Surgical mesh \\
\hline OXC & Mesh, surgical, absorbable, staple line reinforcement & 2 & [878.3300] & Surgical mesh \\
\hline owZ & Mesh, surgical, absorbable, thoracic, chest wall reconstruction & 2 & {$[878.3300]$} & Surgical mesh \\
\hline OWU & Mesh, surgical, non-absorbable, diaphragmatic hernia & 2 & {$[878.3300]$} & Surgical mesh \\
\hline OXJ & Mesh, surgical, non-absorbable, large abdominal wall defects & 2 & {$[878.3300]$} & Surgical mesh \\
\hline owX & Mesh, surgical, non-absorbable, orthopaedics, reinforcement of tendon & 2 & {$[878.3300]$} & Surgical mesh \\
\hline OXG & Mesh, surgical, non-absorbable, plastic and reconstructive surgery & 2 & {$[878.3300]$} & Surgical mesh \\
\hline OXD & Mesh, surgical, non-absorbable, staple line reinforcement & 2 & {$[878.3300]$} & Surgical mesh \\
\hline OXA & Mesh, surgical, non-absorbable, thoracic, chest wall reconstruction & 2 & {$[878.3300]$} & Surgical mesh \\
\hline LBP & Replacement, ossicular (stapes) using absorbable gelatin material & 2 & [874.3450] & Partial ossicular replacement prosthesis \\
\hline OLL & Septal stapler/absorbable staples & 2 & [878.4750] & ImplanTABLE staple \\
\hline MNU & Staple, absorbable & 2 & {$[888.3030]$} & $\begin{array}{l}\text { Single/multiple component metallic bone fixation } \\
\text { appliances and accessories }\end{array}$ \\
\hline GAK & Suture, absorbable & 2 & {$[878.4830]$} & Absorbable surgical gut suture \\
\hline GAL & Suture, absorbable, natural & 2 & {$[878.4830]$} & Absorbable surgical gut suture \\
\hline HMO & Suture, absorbable, ophthalmic & 3 & & \\
\hline GAN & Suture, absorbable, synthetic & 2 & {$[878.4830]$} & Absorbable surgical gut suture \\
\hline GAM & Suture, absorbable, synthetic, polyglycolic acid & 2 & [878.4493] & Absorbable poly(glycolide/l-lactide) surgical suture \\
\hline NEW & Suture, surgical, absorbable, polydioxanone & 2 & {$[878.4840]$} & Absorbable polydioxanone surgical suture \\
\hline
\end{tabular}

a) Note: the results obtained from online search for the device term "absorbable" that was conducted on 6 Aug 2016 at: http://www.accessdata.fda.gov/scripts/cdrh/cfdocs/cfPCD/classification.cfm. 
material or substance that either directly or through intended degradation can pass through or be metabolized or assimilated by cells and/or tissue." The standard's nomenclature appendix further elaborates on its preference for "absorbable" since the prefix "bio-" is redundant in the context of implant applications [43].

Clearly, these two terms of "biodegradable metals" and "absorbable metallic materials" share the same connotation, which defines the complete mission of an intentionally degradable material when implanted in vivo. In the context of biodegradable metals/absorbable metallic materials, the process includes the corrosion caused by body fluid, a host response caused by corrosion products, followed by dissolution/absorption and finally improved tissue healing. The "biodegradation" instead of "biocorrosion" is used to distinguish this new kind of metals which can fully dissolve in vivo with no implant residues. Besides biodegradation process, the following dynamic process of dissolution/absorption also starts in vivo. For example, dissolved $\mathrm{Mg}^{2+}$ is considered to enhance the integrin mediated human-bone-derived cell adhesion and affect new bone formation [48]. The metabolic reaction is also crucial and even more important for biodegradable metals as it is helpful. It is another distinction from traditional metals used for biomedical application. In fact, the different usage habit forming of "biodegradable" or "absorbable"/"bioabsorbable" may be more related with the study field the researchers in. Taking the "absorbable" metallic stent as an example (Fig. 2), once the "absorbable" metallic stent was implanted into blood vessel, "corrosion" of biometal begins. The corrosion products including debris, hydrogen (for Mg-based metals), metallic ions and hydroxyl convert the local environment and diffuse into the blood vessel wall. Some corrosion products can be biologically beneficial. For instance, the diffused and absorbed $\mathrm{Zn}^{2+}$ can potentially play a positive role in dealing with atherosclerosis [49]. Along with the corrosion process, healing processes such as endothelialization may become enhanced. In summary and within the context of absorbable metals, the adjectives "degradable" and "absorbable" refer to the nature of the biodegradation products of the material/device being metabolically absorbed, an attribute of the host (animal or human body) regardless of whether the implant degrades, corrodes, hydrolyzes, or dissolves [50-52].

\section{Summary quantification of the common terms}

Fig. 3a shows preliminary searching results in Web of Knowledge using "degradable", "absorbable" or "resorbable" along with "material" as key words. The utilization of "degradable" is a bit more frequently than "absorbable", but that of "resorbable" steps down. Meanwhile, the counterpart searching result, when using "bio" as prefix to the adjectives along with "material" as keywords, are presented in Fig. 3b. "Biodegradable material" is the most common utilization which holds $91 \%$ among the expression approach. This is also due to the fact that besides the common utilization in biomaterials, "biodegradable" is also used in a wide range of applications such as clean environment and ecology [53,54].

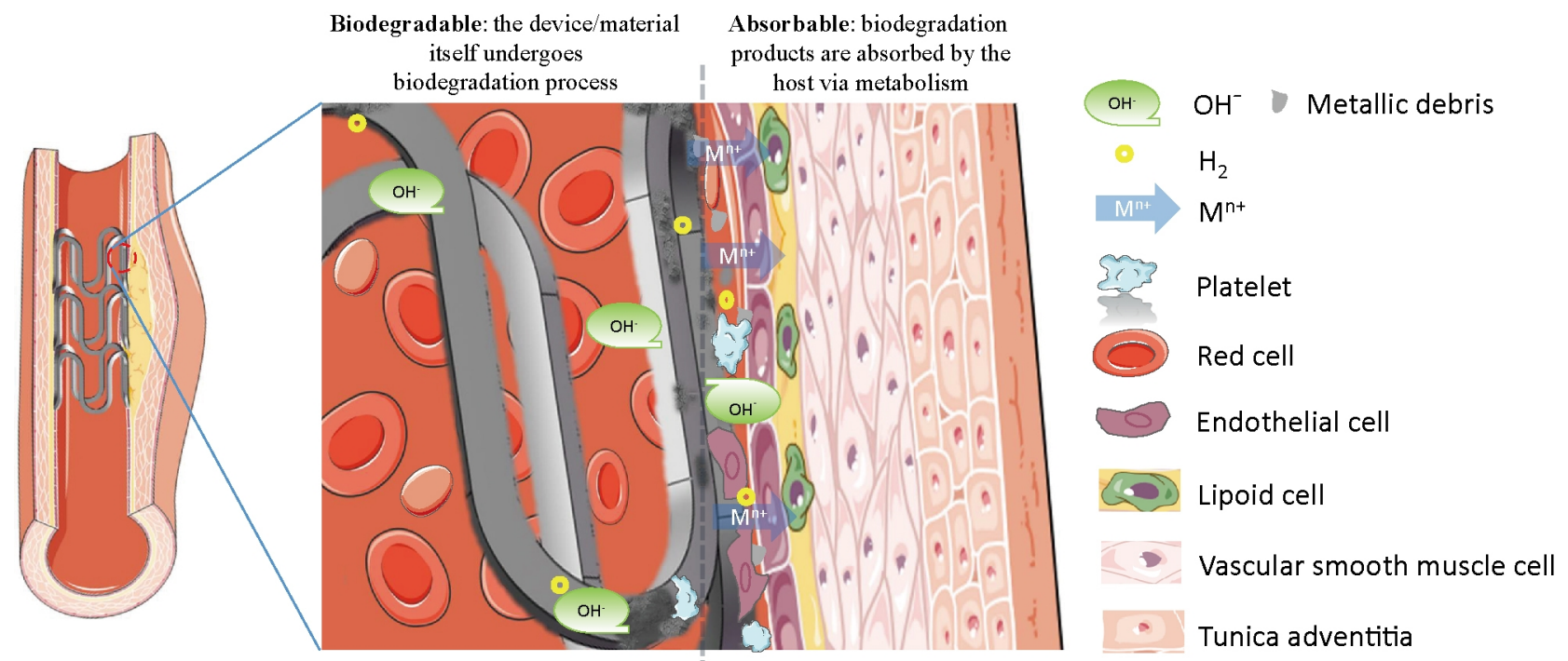

Figure 2 Different point of views on the biodegradation/absorption process. 
a

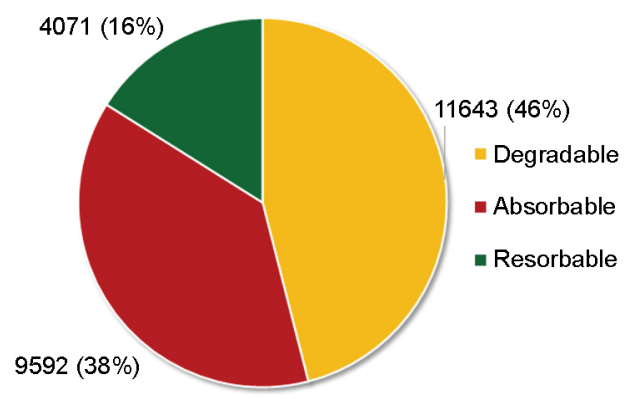

b

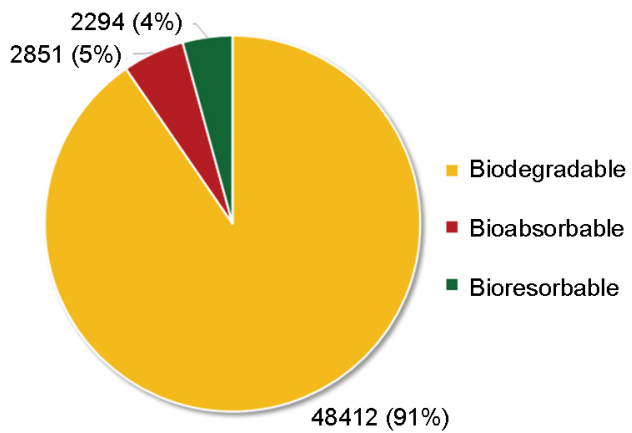

Figure 3 Searching results in Web of Knowledge from all databases: (a) with the total searched publication numbers by "degradable"+ "material", "absorbable"+ "material" and "resorbable"+ "material" as $100 \%$; (b) the total searched publication numbers by "biodegradable"+ "material", "bioabsorbable"+ "material" and "bioresorbable"+ "material" as 100\%.

\section{DISCUSSION}

\section{Expertise inherent biases}

As previously mentioned, biomaterial is an interdisciplinary field fascinating researchers with specialty from different backgrounds. Different backgrounds as well as different research point of interests may be one of the reasons for using different terminologies. Materials scientists tend to focus on the material/device itself, leading to their usage of "biodegradable" to illustrate what happens to the device. They pay more attention to the process such as hydrolysis, corrosion, debris, degradation products and the change of surface morphology, resulting in the researching interests of "material biodegradation". In contrast, surgeons and biomedical researchers tend to be concerned more on the host response and healing process. They are curious about the absorption of various degradation products of the implanted material/device, and related metabolism mechanism, and thereby prefer to use the term "absorbable" to illustrate what happens to the device. As known, some materials may only undergo biodegradation but the corrosion products still have no influence on the metabolic activities. For example, cellulose is considered as "dietary fiber" which cannot be digested and absorbed by human body but is benign for human body [55]. Some coating tablets for drug or drug delivery systems made from cellulose and its derivatives are quite frequently utilized or investigated [56,57]. The polymer and derivatives of cellulose can only be degraded but not be absorbed by human body [58]. For such materials, the adjective "absorbable" or "bioabsorbable" is not appropriate.

Overall, once the materials/devices are implanted into the human body, the "biocorrosion"/biodegradation" process happens immediately, no matter to what degree; at the same time the host will biologically response to the corrosion/degradation products, through the absorption, metabolism and excretion processes. So for the same story, the majority of materials scientists would report it by "biodegradable/degradation" way, whereas the majority of medical doctors would report it by "absorbable/absorption" way. In nature, the two terms "biodegradable metals" and "absorbable metallic materials" share the same connotation and are mutually replaceable.

\section{Connotation and extension of noun forms "biodegradation, bioabsorption and bioresorption" and adjectives "biodegradable, bioabsorbable and bioresorbable"}

The three noun forms of the terms illustrate the process while their adjectival derivatives were used to describe the group of materials with such certain capabilities. For the study on biomaterials, polymer researchers use "degradation/biodegradation" when there is proved chain scission process. Besides, they differentiate "biodegradation" and "degradation" by confirmed metabolic activities between the materials and cells or tissues. Regarding to the four adjectives "biodegradable", "bioabsorbable" and "bioresorbable", the term "biocorrodible" is only used in scientific papers on iron based materials and some patents on magnesium based materials. The common usage of terms "biodegradable", "bioabsorbable" and "bioresorbable" with respect to the biomaterial research area is shown in Table 5. The results reveal a widespread usage of "biodegradable" in both polymers and magnesium based metals. Varies types of materials were reported as biomaterials. Besides, there are also reports of "biodegradable" polymers for ecology and environmental protection, which indicates a further usage scope of "biodegradable" not only for implants and devices. Besides, "bioresorbable" is also utilized in all the research fields of polymers, ceramics and metals. However, no current work used "bioabsorbable" as grammatical 


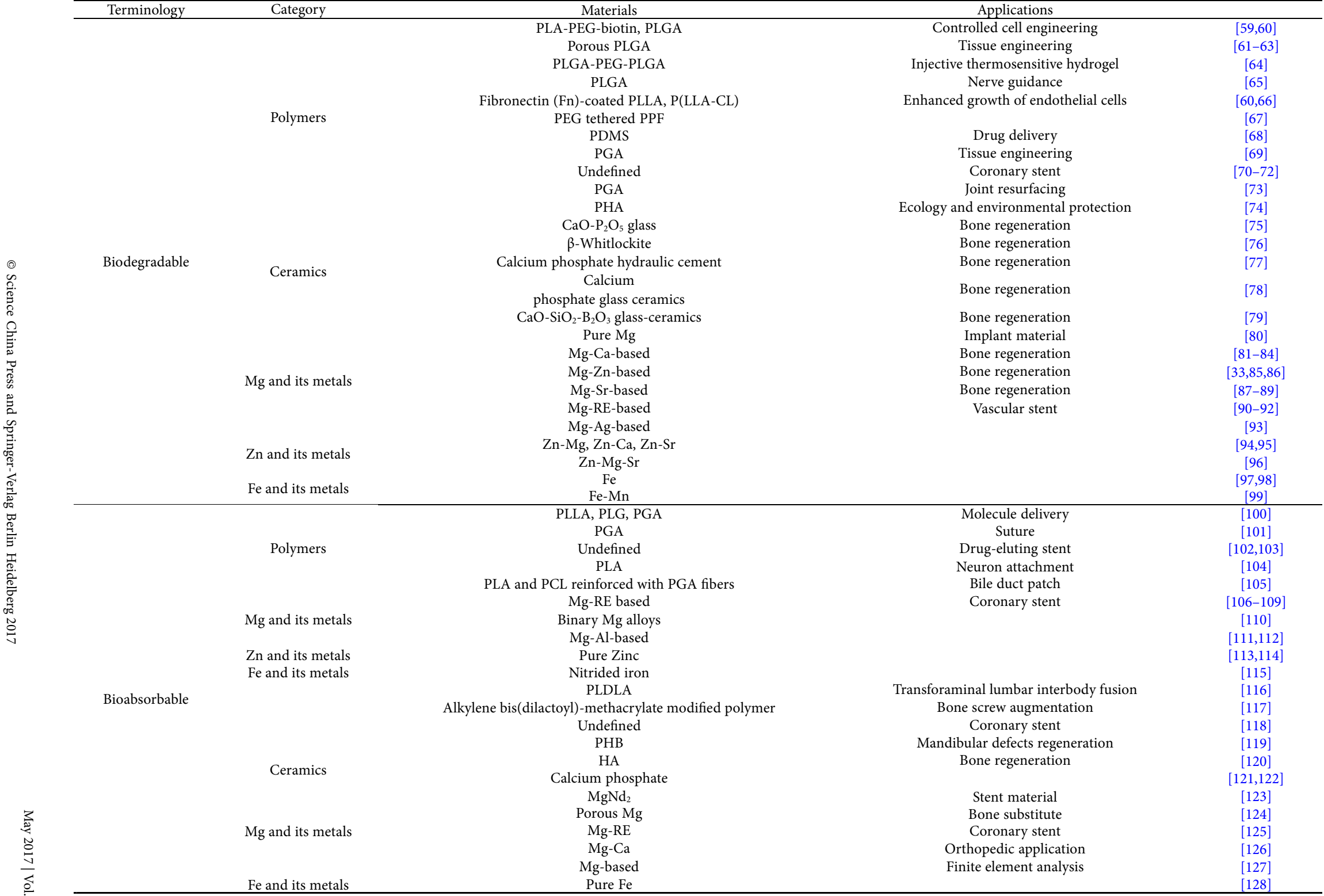


modifier to bioceramics. In addition, as previously illustrated, the prefix "bio" of "bioabsorbable" and "bioresorbable" are abridged, hereafter discussion will concentrate on "biocorrodible", "biodegradable", "absorbable" and "resorbable".

Since absorbable technologies are increasingly utilized in numerous new and broader implant applications, it becomes more important to not acquiesce in addressing historical problems and instead actively move forward toward utilizing standardized language that is both technically accurate and unified in its meaning. Preferred language needs to accurately communicate the concept. To achieve the unifying goal of harmonized terminology, the medical and scientific communities need to not solely look at materials, chemistry, or even biomaterials alone, but to instead look at term selection both across and within the context of the broader medical discipline-the location where the results of implant technology development actually reaches the marketplace where therapies are brought to those in need. Nomenclature solutions need to both understand and respond to the context of terms across adjacent technologies, which means to address needs from the perspectives of the biomaterial researcher, the device/product developer, the surgeon/clinician user, the regulator, and, last but not least, the patient/general public who is the direct beneficiary of the developed technology.

A better understanding of these terminologies is necessary and beneficial to the field. Therefore, the definitions on "degradable", "absorbable", "resorbable" and related terms proposed by different organizations in different fields have been summarized and discussed, with the connotation and extension of each term being compared and the criteria being proposed.

\section{CONCLUDING REMARKS}

Herein, given both the searching problem on the Internet and ambiguity in meanings, the usage of grammatical modifiers to describe biomaterials that is eventually absorbed by human body has been enumerated, based on usage habits, laws, standards and markets. In summary, "degradable"/“biodegradable" are the most frequently used grammatical modifier not only in metals but also polymers as such kind of biomaterials. "Biodegradation" and "biodegradable" define the change of the material/device well in the research of biomaterials, but they are also adopted in other fields such as ecology and environmental protection. Meanwhile, "resorbable"/“bioresorbable" have long been recognized in the biological research and the "resorption" itself has been widely accepted as a biological reaction. The utilization of "resorbable"/"bioresorbable" was found to be not as frequent as the counterparts "degradable"/“biodegradable" and "absorbable"/“bioabsorbable". Such usage is accurate for osteoclast driven bone resorption, but is inappropriate for implants that do not carry the potential to grow back into their original form. Otherwise, despite it is not the most frequently used term, "absorbable"/"bioabsorbable" concentrates more on the host metabolism to the foreign biodegradation products of the implanted material/device compared with "degradable"/"biodegradable". "Absorbable" is defined in the scope of biomaterials by different organizations and their publications and also adopted by ASTM to illustrate "absorbable polymer". It is the most historically established, the most broadly applicable (includes dissolvable devices that do not degrade), the most specific to medical applications, and is the formal legal descriptor for most implant devices. Considering the usage history, common utilization in law and standards, as well as the scientific meaning in essence, "absorbable" can be better among other grammatical modifiers for description of an implant that is eventually absorbed by the body, which is recommended by the authors for a further internationally-unified usage.

Received 28 February 2017; accepted 27 March 2017;

published online 26 April 2017

1 Mackenzie D. The history of sutures. Med Hist, 1973, 17: 158-168

2 Hench LL. Bioceramics. J Am Ceramic Soc, 2005, 81: 1705-1728

3 Hench LL. Bioceramics: from concept to clinic. J Am Ceramic Soc, 1991, 74: 1487-1510

4 Windhagen $\mathrm{H}$, Radtke $\mathrm{K}$, Weizbauer $\mathrm{A}$, et al. Biodegradable magnesium-based screw clinically equivalent to titanium screw in hallux valgus surgery: short term results of the first prospective, randomized, controlled clinical pilot study. BioMed Eng OnLine, 2013, 12: 62

5 Schildwächter M. Biotronik announces CE mark for magmaris, the first clinically-proven bioresorbable magnesium scaffold. http://www.magmaris.com/en/newsroom/june-15-2016

6 Shalaby SW, Burg KJL. Bioabsorbable polymers update: degradation mechanisms, safety, and application. J App Biomater, 1995, 6: 219-221

7 Vert M, Li SM, Spenlehauer G, et al. Bioresorbability and biocompatibility of aliphatic polyesters. J Mater Sci-Mater Med, 1992, 3: 432-446

8 Vert M. Degradable and bioresorbable polymers in surgery and in pharmacology: beliefs and facts. J Mater Sci-Mater Med, 2009, 20: 437-446

9 Benicewicz BC, Hopper PK. Review: polymers for absorbable surgical sutures-Part I. J Bioactive Compatible Polym, 1990, 5: $453-472$

10 Barrows HT. Synthetic bioabsorbable polymers. In: Szycher M (Ed.). High Performance Biomaterials: A Complete Guide to Medical and Pharmceutical Applications. Boca Raton: CRC PRESS, 1991, 243-257

11 Weiler A, Hoffmann RFG, Stähelin AC, et al. Biodegradable 
implants in sports medicine: the biological base. Arthroscopy-J Arthroscopic Related Surgery, 2000, 16: 305-321

12 Ikada Y, Tsuji H. Biodegradable polyesters for medical and ecological applications. Macromol Rapid Commun, 2000, 21: 117-132

13 Ashammakhi N, Peltoniemi H, Waris E, et al. Developments in craniomaxillofacial surgery: use of self-reinforced bioabsorbable osteofixation devices. Plast Reconstr Surg, 2001, 108: 167-180

14 Vert M, Doi Y, Hellwich KH, et al. Terminology for biorelated polymers and applications (IUPAC Recommendations 2012). Pure Appl Chem, 2012, 84: 377-410

15 The United States Pharmacopeial Convention. The Second Supplement to the Pharmacopeia of the United States of America: 11th decennial revision (USP XI-1939 Supplement). 1939

16 Truhlsen SM. The recession operation: histopathologic response, and suture reaction and absorption. Trans Am Ophthalmol Soc, 1965, 63: 626-677

17 USP in U.S. Law. http://www.usp.org/print/about-usp/legal-recognition/usp-us-law

18 USP develops and publishes standards for drug substances, drug products, excipients, and dietary supplements in the United States Pharmacopeia-National Formulary (USP-NF)

19 United States Public Law 94-295. 1976

20 United States Pharmacopeia. http://www.usp.org/

21 British Pharmacopeia. https://www.pharmacopoeia.com/

22 European Pharmacopoeia. http://online.pheur.org/EN/entry.htm

23 Williams DF. The Williams Dictionary of Biomaterials. Liverpool: Liverpool University Press, 1999

24 https://en.wikipedia.org/wiki/Biodegradation

25 Jones RG, Kahovec J, Stepto R, et al. Compendium of Polymer Terminology and Nomenclature: IUPAC Recommendations 2008. Cambridge: RSC Publishing, 2009

26 Higashi S, Yamamuro T, Nakamura T, et al. Polymer-hydroxyapatite composites for biodegradable bone fillers. Biomaterials, 1986, 7: $183-187$

27 de Groot K. Bioceramics of Calcium Phosphate. Boca Raton: CRC Press, 1983

28 Hollinger JO, Battistone GC. Biodegradable bone repair materials synthetic polymers and ceramics. Clin Orthop Relat Res, 1986, 207 : 290-306

29 ASTM D653-14, Standard Terminology Relating to Soil, Rock, and Contained Fluids. ASTM International, West Conshohocken, PA, 2014. https://www.astm.org/Standards/D653.htm

30 Witte F, Hort N, Vogt C, et al. Degradable biomaterials based on magnesium corrosion. Curr Opin Solid State Mater Sci, 2008, 12: 63-72

31 Lynn DM, Langer R. Degradable poly( $\beta$-amino esters): synthesis, characterization, and self-assembly with plasmid DNA. J Am Chem Soc, 2000, 122: 10761-10768

32 Cima LG, Vacanti JP, Vacanti C, et al. Tissue engineering by cell transplantation using degradable polymer substrates. J Biomech Eng, 1991, 113: 143-151

33 Zhang S, Zhang X, Zhao C, et al. Research on an Mg-Zn alloy as a degradable biomaterial. Acta Biomater, 2010, 6: 626-640

34 Anseth KS, Metters AT, Bryant SJ, et al. In situ forming degradable networks and their application in tissue engineering and drug delivery. J Control Release, 2002, 78: 199-209

35 Forrest ML, Koerber JT, Pack DW. A degradable polyethylenimine derivative with low toxicity for highly efficient gene delivery. Bioconjugate Chem, 2003, 14: 934-940

36 ASTM E2747-11, Standard Specification for Evaluation and Selection of Onsite Offices for Environmentally Sustainable Meetings, Events, Trade Shows, and Conferences. ASTM International,
West Conshohocken, PA, 2011. https://www.astm.org/Standards/E2747.htm

37 ASTM E2745-11, Standard Specification for Evaluation and Selection of Audio Visual (AV) and Production for Environmentally Sustainable Meetings, Events, Trade Shows, and Conferences. ASTM International, West Conshohocken, PA, 2011. https://www.astm.org/Standards/E2745.htm

38 ASTM E2746-11, Standard Specification for Evaluation and Selection of Communication and Marketing Materials for Environmentally Sustainable Meetings, Events, Trade Shows, and Conferences. ASTM International, West Conshohocken, PA, 2011. https://www.astm.org/Standards/E2746.htm

39 ASTM E2741-11, Standard Specification for Evaluation and Selection of Destinations for Environmentally Sustainable Meetings, Events, Trade Shows, and Conferences. ASTM International, West Conshohocken, PA, 2011. https://www.astm.org/Standards/E2741.htm

400 ASTM E2773-11, Standard Specification for Evaluation and Selection of Food and Beverage for Environmentally Sustainable Meetings, Events, Trade Shows, and Conferences. ASTM International, West Conshohocken, PA, 2011. https://www.astm.org/Standards/E2773.htm

41 ASTM E2742-11, Standard Specification for Evaluation and Selection of Exhibits for Environmentally Sustainable Meetings, Events, Trade Shows, and Conferences. ASTM International, West Conshohocken, PA, 2011. https://www.astm.org/Standards/E2742.htm

42 ASTM E2774-11, Standard Specification for Evaluation and Selection of Venues for Environmentally Sustainable Meetings, Events, Trade Shows, and Conferences. ASTM International, West Conshohocken, PA, 2011. https://www.astm.org/Standards/E2774.htm

43 ASTM F2902-12, Standard Guide for Assessment of Absorbable Polymeric Implants. ASTM International, West Conshohocken, PA, 2012. https://www.astm.org/Standards/F2902.htm

44 https://en.wikipedia.org/wiki/Resorption

45 Venes D. Taber's Cyclopedic Medical Dictionary, 22th edition. Philadelphia: F. A. Davis Company, 2013

46 Zheng YF, Gu XN, Witte F. Biodegradable metals. Mater Sci EngR-Rep, 2014, 77: 1-34

47 Hanawa T. Metal ion release from metal implants. Mater Sci Eng-C, 2004, 24: 745-752

48 Zreiqat H, Howlett CR, Zannettino A, et al. Mechanisms of magnesium-stimulated adhesion of osteoblastic cells to commonly used orthopaedic implants. J Biomed Mater Res, 2002, 62: 175-184

49 Little PJ, Bhattacharya R, Moreyra AE, et al. Zinc and cardiovascular disease. Nutrition, 2010, 26: 1050-1057

50 Seager H. Drug-delivery products and the Zydis fast-dissolving dosage form. J Pharm Pharmacol, 1998, 50: 375-382

51 Shikinami Y. Shape-memory, biodegradable and absorbable material. U.S. Patent No. 6,281,262, 2001-8-28

52 Huitema TW, Knight GW, Ransick MH, Schulze DR. Surgical implant with preferential corrosion zone. U.S. Patent No. 7,905,902, 2011-3-15

53 Luzier WD. Materials derived from biomass/biodegradable materials. Proc Natl Acad Sci USA, 1992, 89: 839-842

54 Gross RA, Kalra B. Biodegradable polymers for the environment. Science, 2002, 297: 803-807

55 Trumbo P, Schlicker S, Yates AA, et al. Dietary reference intakes for energy, carbohydrate, fiber, fat, fatty acids, cholesterol, protein and amino acids. J Am Diet Assoc, 2002, 102: 1621-1630

56 Chambin O, Champion D, Debray C, et al. Effects of different cellulose derivatives on drug release mechanism studied at a preformulation stage. J Control Release, 2004, 95: 101-108 
57 Fundueanu G, Constantin M, Esposito E, et al. Cellulose acetate butyrate microcapsules containing dextran ion-exchange resins as self-propelled drug release system. Biomaterials, 2005, 26: 4337-4347

58 Märtson M, Viljanto J, Hurme T, et al. Is cellulose sponge degradable or stable as implantation material? An in vivo subcutaneous study in the rat. Biomaterials, 1999, 20: 1989-1995

59 Patel N, Padera R, Sanders GH, et al. Spatially controlled cell engineering on biodegradable polymer surfaces. The FASEB journal, 1998, 12: 1447-1454

60 Goldstein A. Effect of convection on osteoblastic cell growth and function in biodegradable polymer foam scaffolds. Biomaterials, 2001, 22: 1279-1288

$61 \mathrm{Wu} \mathrm{L}$, Ding J. In vitro degradation of three-dimensional porous poly(D,L-lactide-co-glycolide) scaffolds for tissue engineering. Biomaterials, 2004, 25: 5821-5830

62 Wu L, Ding J. Effects of porosity and pore size on in vitro degradation of three-dimensional porous poly(D,L-lactide-co-glycolide) scaffolds for tissue engineering. J Biomed Mater Res, 2005, 75A: 767-777

63 Pan Z, Ding J. Poly(lactide-co-glycolide) porous scaffolds for tissue engineering and regenerative medicine. Interface Focus, 2012, 2: 366-377

64 Yu L, Zhang Z, Zhang H, et al. Biodegradability and biocompatibility of thermoreversible hydrogels formed from mixing a sol and a precipitate of block copolymers in water. Biomacromolecules, 2010, 11: 2169-2178

65 Wen X, Tresco PA. Fabrication and characterization of permeable degradable poly(DL-lactide-co-glycolide) (PLGA) hollow fiber phase inversion membranes for use as nerve tract guidance channels. Biomaterials, 2006, 27: 3800-3809

66 Chu CFL, Lu A, Liszkowski M, et al. Enhanced growth of animal and human endothelial cells on biodegradable polymers. BBA-Gen Subjects, 1999, 1472: 479-485

67 Jo S, Engel PS, Mikos AG. Synthesis of poly(ethylene glycol)-tethered poly(propylene fumarate) and its modification with GRGD peptide. Polymer, 2000, 41: 7595-7604

68 Park JH, Allen MG, Prausnitz MR. Biodegradable polymer microneedles: fabrication, mechanics and transdermal drug delivery. J Control Release, 2005, 104: 51-66

69 Freed LE, Vunjak-Novakovic G, Biron RJ, et al. Biodegradable polymer scaffolds for tissue engineering. Nat Biotechnol, 1994, 12: 689-693

70 Windecker S, Serruys PW, Wandel S, et al. Biolimus-eluting stent with biodegradable polymer versus sirolimus-eluting stent with durable polymer for coronary revascularisation (LEADERS): a randomised non-inferiority trial. Lancet, 2008, 372: 1163-1173

71 Stefanini GG, Kalesan B, Serruys PW, et al. Long-term clinical outcomes of biodegradable polymer biolimus-eluting stents versus durable polymer sirolimus-eluting stents in patients with coronary artery disease (LEADERS): 4 year follow-up of a randomised non-inferiority trial. Lancet, 2011, 378: 1940-1948

72 Raungaard B, Jensen LO, Tilsted $\mathrm{HH}$, et al. Zotarolimus-eluting durable-polymer-coated stent versus a biolimus-eluting biodegradable-polymer-coated stent in unselected patients undergoing percutaneous coronary intervention (SORT OUT VI): a randomised non-inferiority trial. Lancet, 2015, 385: 1527-1535

73 Freed LE, Grande DA, Lingbin Z, et al. Joint resurfacing using allograft chondrocytes and synthetic biodegradable polymer scaffolds. J Biomed Mater Res, 1994, 28: 891-899

74 Poirier Y, Nawrath C, Somerville C. Production of polyhydroxyalkanoates, a family of biodegradable plastics and elastomers, in bacteria and plants. Nat Biotechnol, 1995, 13: 142-150

75 Dias A, Tsuru K, Hayakawa S, et al. Crystallisation studies of biodegradable $\mathrm{CaO}-\mathrm{P}_{2} \mathrm{O}_{5}$ glass with $\mathrm{MgO}$ and $\mathrm{TiO}_{2}$ for bone regeneration applications. Glass Technol, 2004, 45: 78-79

76 Klein CPAT, de Groot K, Drissen AA, et al. Interaction of biodegradable $\beta$-whitlockite ceramics with bone tissue: an in vivo study. Biomaterials, 1985, 6: 189-192

77 Ikenaga M, Hardouin P, Lemaître J, et al. Biomechanical characterization of a biodegradable calcium phosphate hydraulic cement: a comparison with porous biphasic calcium phosphate ceramics. J Biomed Mater Res, 1998, 40: 139-144

78 Dias AG, Lopes MA, Santos JD, et al. In vivo performance of biodegradable calcium phosphate glass ceramics using the rabbit model: histological and SEM observation. J Biomater Appl, 2006, 20: $253-266$

79 Lee JH, Lee CK, Chang BS, et al. In vivo study of novel biodegradable and osteoconductive $\mathrm{CaO}-\mathrm{SiO}_{2}-\mathrm{B}_{2} \mathrm{O}_{3}$ glass-ceramics. J Biomed Mater Res, 2006, 77A: 362-369

80 Song $\mathrm{G}$, Song S. A possible biodegradable magnesium implant material. Adv Eng Mater, 2007, 9: 298-302

81 Kim WC, Kim JG, Lee JY, et al. Influence of Ca on the corrosion properties of magnesium for biomaterials. Mater Lett, 2008, 62: 4146-4148

82 Li Z, Gu X, Lou S, et al. The development of binary Mg-Ca alloys for use as biodegradable materials within bone. Biomaterials, 2008, 29: 1329-1344

83 Wan Y, Xiong G, Luo H, et al. Preparation and characterization of a new biomedical magnesium-calcium alloy. Mater Des, 2008, 29: 2034-2037

84 Seong JW, Kim WJ. Development of biodegradable $\mathrm{Mg}$-Ca alloy sheets with enhanced strength and corrosion properties through the refinement and uniform dispersion of the $\mathrm{Mg}_{2} \mathrm{Ca}$ phase by highratio differential speed rolling. Acta Biomater, 2015, 11: 531-542

85 Zhang S, Li J, Song Y, et al. In vitro degradation, hemolysis and MC3T3-E1 cell adhesion of biodegradable Mg-Zn alloy. Mater Sci Eng-C, 2009, 29: 1907-1912

86 Li J, Song Y, Zhang S, et al. In vitro responses of human bone marrow stromal cells to a fluoridated hydroxyapatite coated biodegradable Mg-Zn alloy. Biomaterials, 2010, 31: 5782-5788

87 Brar HS, Wong J, Manuel MV. Investigation of the mechanical and degradation properties of $\mathrm{Mg}-\mathrm{Sr}$ and $\mathrm{Mg}-\mathrm{Zn}-\mathrm{Sr}$ alloys for use as potential biodegradable implant materials. J Mech Behav Biomed Mater, 2012, 7: 87-95

88 Bornapour M, Muja N, Shum-Tim D, et al. Biocompatibility and biodegradability of $\mathrm{Mg}$-Sr alloys: the formation of Sr-substituted hydroxyapatite. Acta Biomater, 2013, 9: 5319-5330

$89 \mathrm{Gu} \mathrm{XN}, \mathrm{Xie} \mathrm{XH}, \mathrm{Li} \mathrm{N}$, et al. In vitro and in vivo studies on a $\mathrm{Mg}$-Sr binary alloy system developed as a new kind of biodegradable metal. Acta Biomater, 2012, 8: 2360-2374

90 Hänzi AC, Gerber I, Schinhammer M, et al. On the in vitro and in vivo degradation performance and biological response of new biodegradable Mg-Y-Zn alloys. Acta Biomater, 2010, 6: 1824-1833

91 Chou DT, Hong D, Saha $\mathrm{P}$, et al. In vitro and in vivo corrosion, cytocompatibility and mechanical properties of biodegradable Mg-Y-Ca-Zr alloys as implant materials. Acta Biomater, 2013, 9: 8518-8533

92 Zong Y, Yuan G, Zhang X, et al. Comparison of biodegradable behaviors of AZ31 and Mg-Nd-Zn-Zr alloys in Hank's physiological solution. Mater Sci Eng-B, 2012, 177: 395-401

93 Tie D, Feyerabend F, Müller WD, et al. Antibacterial biodegradable Mg-Ag alloys. Eur Cell Mater, 2013, 25: 284-298

94 Vojtěch D, Kubásek J, Serák J, et al. Mechanical and corrosion prop- 
erties of newly developed biodegradable Zn-based alloys for bone fixation. Acta Biomater, 2011, 7: 3515-3522

95 Li H, Yang H, Zheng Y, et al. Design and characterizations of novel biodegradable ternary $\mathrm{Zn}$-based alloys with IIA nutrient alloying elements Mg, Ca and Sr. Mater Des, 2015, 83: 95-102

96 Liu X, Sun J, Yang Y, et al. Microstructure, mechanical properties, in vitro degradation behavior and hemocompatibility of novel $\mathrm{Zn}-\mathrm{Mg}$-Sr alloys as biodegradable metals. Mater Lett, 2016, 162: 242-245

97 Wu C, Qiu H, Hu X, et al. Short-term safety and efficacy of the biodegradable iron stent in mini-swine coronary arteries. Chin Med J (Engl), 2013, 126: 4752-4757

98 Purnama A, Hermawan H, Champetier S, et al. Gene expression profile of mouse fibroblasts exposed to a biodegradable iron alloy for stents. Acta Biomater, 2013, 9: 8746-8753

99 Hermawan H, Purnama A, Dube D, et al. Fe-Mn alloys for metallic biodegradable stents: degradation and cell viability studies. Acta Biomater, 2010, 6: 1852-1860

100 Sheridan MH, Shea LD, Peters MC, et al. Bioabsorbable polymer scaffolds for tissue engineering capable of sustained growth factor delivery. J Control Release, 2000, 64: 91-102

101 Shawe S, Buchanan F, Harkin-Jones E, et al. A study on the rate of degradation of the bioabsorbable polymer polyglycolic acid (PGA). J Mater Sci, 2006, 41: 4832-4838

102 Palmerini T, Biondi-Zoccai G, Della Riva D, et al. Clinical outcomes with bioabsorbable polymer-versus durable polymer-based drug-eluting and bare-metal stents. J Am Coll Cardiol, 2014, 63: 299-307

103 Tanimoto S, Serruys PW, Thuesen L, et al. Comparison of in vivo acute stent recoil between the bioabsorbable everolimus-eluting coronary stent and the everolimus-eluting cobalt chromium coronary stent: insights from the ABSORB and SPIRIT trials. Catheter Cardiovasc Interv, 2007, 70: 515-523

104 Tsuji H, Sasaki H, Sato H, et al. Neuron attachment properties of carbon negative-ion implanted bioabsorbable polymer of poly-lactic acid. Nucl Instr Meth Phys Res Sect B-Beam Interact Mater Atoms, 2002, 191: 815-819

105 Aikawa M, Miyazawa M, Okamoto K, et al. A novel treatment for bile duct injury with a tissue-engineered bioabsorbable polymer patch. Surgery, 2010, 147: 575-580

106 Waksman R, Pakala R, Kuchulakanti PK, et al. Safety and efficacy of bioabsorbable magnesium alloy stents in porcine coronary arteries. Catheter Cardiovasc Interv, 2006, 68: 607-617

107 Di Mario C, Griffiths H, Goktekin O, et al. Drug-eluting bioabsorbable magnesium stent. J Interv Cardiol, 2004, 17: 391-395

108 Erbel R, Di Mario C, Bartunek J, et al. Temporary scaffolding of coronary arteries with bioabsorbable magnesium stents: a prospective, non-randomised multicentre trial. Lancet, 2007, 369: 1869-1875

109 Schranz D, Zartner P, Michel-Behnke I, et al. Bioabsorbable metal stents for percutaneous treatment of critical recoarctation of the aorta in a newborn. Catheter Cardiovasc Interv, 2006, 67: 671-673

$110 \mathrm{Gu} \mathrm{X}$, Zheng Y, Cheng Y, et al. In vitro corrosion and biocompatibility of binary magnesium alloys. Biomaterials, 2009, 30: 484-498

111 Hiromoto S, Inoue M, Taguchi $\mathrm{T}$, et al. In vitro and in vivo biocompatibility and corrosion behaviour of a bioabsorbable magnesium alloy coated with octacalcium phosphate and hydroxyapatite. Acta Biomater, 2015, 11: 520-530

112 Hiromoto S, Tomozawa M, Maruyama N. Fatigue property of a bioabsorbable magnesium alloy with a hydroxyapatite coating formed by a chemical solution deposition. J Mech Behav Biomedical Mater, 2013, 25: 1-10
113 Bowen PK, Drelich J, Goldman J. Zinc exhibits ideal physiological corrosion behavior for bioabsorbable stents. Adv Mater, 2013, 25: $2577-2582$

114 Liu X, Sun J, Yang Y, et al. In vitro investigation of ultra-pure Zn and its mini-tube as potential bioabsorbable stent material. Mater Lett, 2015, 161: 53-56

115 Lin W, Zhang G, Cao P, et al. Cytotoxicity and its test methodology for a bioabsorbable nitrided iron stent. J Biomed Mater Res, 2015, 103: $764-776$

116 Coe JD, Vaccaro AR. Instrumented transforaminal lumbar interbody fusion with bioresorbable polymer implants and iliac crest autograft. Spine, 2005, 30: S76-S83

117 Ignatius AA, Augat P, Ohnmacht M, et al. A new bioresorbable polymer for screw augmentation in the osteosynthesis of osteoporotic cancellous bone: a biomechanical evaluation. J Biomed Mater Res, 2001, 58: 254-260

118 Krucoff MW, Kereiakes DJ, Petersen JL, et al. A novel bioresorbable polymer paclitaxel-eluting stent for the treatment of single and multivessel coronary disease. J Am Coll Cardiol, 2008, 51: 1543-1552

119 Kostopoulos L, Karring T. Guided bone regeneration in mandibular defects in rats using a bioresorbable polymer. Clin Oral Implants Res, 1994, 5: 66-74

120 Dubok VA. Bioceramics-yesterday, today, tomorrow. Powder Metall Metal Ceram, 2000, 39: 381-394

121 Safronova T, Kuznetsov A, Korneychuk S, et al. Calcium phosphate powders synthesized from solutions with $\left[\mathrm{Ca}^{2+}\right] /\left[\mathrm{PO}_{4}{ }^{3-}\right]=1$ for bioresorbable ceramics. Cent Eur J Chem, 2009, 7: 184-191

122 Bohner M. Bioresorbable ceramics. In: Buchanan FJ (Ed.). Degradation Rate of Bioresorbable Materials. Cambridge: Woodhead Publishing, 2008, 95-114

123 Seitz JM, Eifler R, Stahl J, et al. Characterization of $\mathrm{MgNd}_{2}$ alloy for potential applications in bioresorbable implantable devices. Acta Biomater, 2012, 8: 3852-3864

124 Wen CE, Yamada Y, Shimojima K, et al. Porous bioresorbable magnesium as bone substitute. MSF, 2003, 419-422: 1001-1006

125 Campos CM, Muramatsu T, Iqbal J, et al. Bioresorbable drug-eluting magnesium-alloy scaffold for treatment of coronary artery disease. Int J Mol Sci, 2013, 14: 24492-24500

126 Kirkland NT, Birbilis N, Walker J, et al. In-vitro dissolution of magnesium-calcium binary alloys: clarifying the unique role of calcium additions in bioresorbable magnesium implant alloys. J Biomed Mater Res, 2010, 95B: 91-100

127 Gastaldi D, Sassi V, Petrini L, et al. Continuum damage model for bioresorbable magnesium alloy devices - application to coronary stents. J Mech Behav Biomed Mater, 2011, 4: 352-365

128 Kitabata H, Waksman R, Warnack B. Bioresorbable metal scaffold for cardiovascular application: current knowledge and future perspectives. Cardiovasc Revasc Med, 2014, 15: 109-116

Acknowledgments This work was supported by the National Key Research and Development Program of China (2016YFC1102402), National Natural Science Foundation of China (NSFC, 51431002), and the NSFC and the Research Grants Council (RGC) of Hong Kong Joint Research Scheme (51361165101 and 5161101031)

Author contributions Liu Y prepared the figures, tables, organized the references and wrote the paper. Zheng Y provided the overall concept and revised the manuscript. Hayes B helped with the standard development and revised the manuscript. All authors participated in the discussion.

Conflict of interest The authors declare that they have no conflict of interest. 

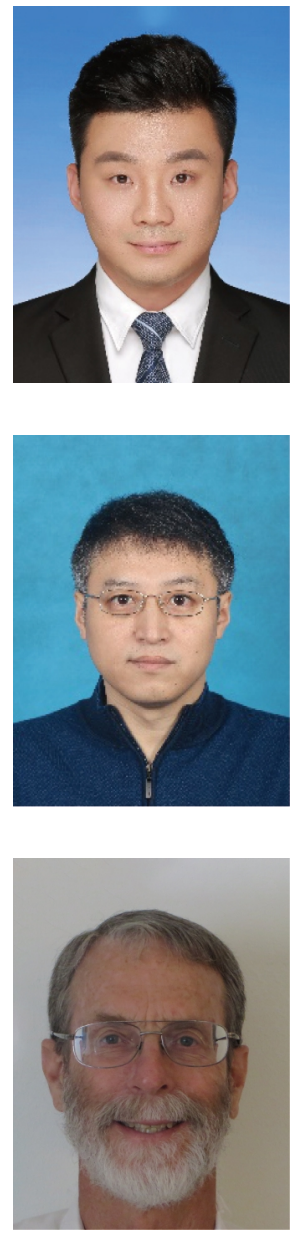

Yang Liu received his bachelor degree in materials science and engineering from Harbin engineering University in 2013. Then he continued his study as a PhD candidate in Prof. Yufeng Zheng's Lab in Peking University. His research interests are mainly focused on the corrosion study of absorbable metallic biomaterials, as well as the development of new kind of Mg-based biomaterials.

Yufeng Zheng obtained his PhD degree from Harbin Institute of Technology in 1998. He is the National Outstanding Youth and Yangtze River scholar of China. His research interests are focused on the development of novel biomaterials and application and design of biomedical devices.

Byron Hayes, an over 35 year employee of W.L. Gore, has been involved in the commercial development of multiple absorbable polymeric implants since the late 1980s. Hayes started his standards development activities with ASTM in 2000, where he is actively developing standards for polymeric and metallic absorbable implants. In 2010, Hayes also became involved with ISO Technical Committees TC150 and TC194 and is now convener of working groups focused on cardiovascular and metallic absorbable implants.

\section{可降解、可吸收、再吸收——哪个是描述最终被人体吸收生物材料的最好词汇?}

刘洋 ${ }^{1}$, 郑玉峰 ${ }^{*}$, 拜伦海耶斯 ${ }^{2}$

摘要 关于最终被人体吸收的植入材料, 领域内文献采用的英文修饰词长期以来混乱且不同, 不仅造成文献检索困难, 同时模糊了研究人 员的研究边界. 此领域在法律法规/标准中统一用词的确定, 为领域内的科学研究、产品销售及产品使用说明奠定了基础. 我们基于化学、 生态学、材料学、生物学、微生物学和药学, 立足于使用习惯、法律、标准和市场, 对领域内使用已久的典型修饰词“生物可降解”、“再 吸收”和“可吸收”进行了讨论和解释. 总的来说, 尽管目前绝大多数修饰语实际想表达的意思相同, 作者认为“可吸收”这一英文修饰语是最 恰当的修饰词. 同时, 我们提议进一步规范和统一该领域修饰词的使用. 